\title{
Modeling of a Prosumer in Intelligent Integrated Energy Systems
}

\author{
Evgeny Barakhtenko ${ }^{1, *}$, Dmitry Sokolov ${ }^{1}$, and Veronika Shelekhova ${ }^{1}$ \\ ${ }^{1}$ Melentiev Energy Systems Institute of Siberian Branch of the Russian Academy of Sciences (ESI SB \\ RAS), Pipeline Energy Systems Department, 130, Lermontov str., Irkutsk, Russia, 664033
}

\begin{abstract}
The integration of many energy systems of various types (electricity, heat, cooling, etc.) into a single technological entity involves the use of new information and communication technologies and a holistic multi-level automated control system, which provides the establishment of integrated intelligent energy systems. In such systems, the consumer can both provide themselves with various types of energy, and supply energy into the energy system. The paper presents a methodology for modeling the prosumer in intelligent integrated energy systems. The methodology includes the following components: a mathematical model of the prosumer in intelligent electricity, heat/cooling systems; a method of choosing the energy sources to cover their load with minimal costs of electricity, heat/cooling generation. The methodology developed for modeling the prosumer in intelligent electric, heat/cooling systems was implemented in software. The presented results are tested on a test energy supply scheme.
\end{abstract}

\section{Introduction}

The integration of many separate systems into a single technological complex ensures the implementation of new functional capabilities, the use of more advanced technologies in operation, and the construction of integrated intelligent systems with coordinated control of their operation, as well as active participation of the consumer in the energy supply process [1-5]. In such energy systems, the end user is considered as a partner of energy entities in terms of ensuring reliable operation of the energy system, acquires the status of an active one and becomes one of the main elements in the energy system [6]. These consumers can independently set the requirements of the amount of energy to be received, its quality and consumer properties, and energy services [7-10].

Design of the load-controlled consumption systems, including heterogeneous energy sources and storage devices usually involves solving a mixed integer linear programming problem [11-12]. Some researchers [13-16] use multi-criteria optimization to consider not only the investment and operational costs in the design of energy systems, but also compensation for the energy generation-related emissions of pollutants.

The switch to the intelligent energy industry based on a customer-oriented approach generates the need to develop a methodological support for the study of prosumer

\footnotetext{
*Corresponding author: barakhtenko@isem.irk.ru
} 
consumption, which is a pressing scientific problem of great importance for the national energy development. In this paper, we propose an approach to modeling of the prosumer. This approach makes it possible based on a redundant energy supply scheme to choose an optimal mix of generating equipment to meet the consumer needs for various types of energy, given its transport.

\section{Statement of the problem}

The set parameters include: a set of electricity sources $I=I_{\mathrm{E}} \cup I_{\mathrm{N}}$, consisting of sets of existing $I_{\mathrm{E}}$ and new $I_{\mathrm{N}}$ ones; a set of heat sources $J=J_{\mathrm{E}} \cup J_{\mathrm{N}}$, consisting of sets of existing $J_{\mathrm{E}}$ and new $J_{\mathrm{N}}$ ones; a set of cooling energy sources, consisting of sets of existing $D_{\mathrm{E}}$ and new $D_{\mathrm{N}}$ ones, here $J \subset D$; a set of combined heat and power plants (CHPP) $C H P=\left(I_{\mathrm{E}}, J_{\mathrm{E}}\right), I_{\mathrm{E}} \subset I, J_{\mathrm{E}} \subset J$; the cost of primary energy resources to produce electricity $S_{t, i}^{\mathrm{EL}}, i \in I$, heat $S_{t, j}^{\mathrm{HE}}, j \in J$ and cooling energy $S_{t, d}^{\mathrm{CO}}, d \in D$ at time $t$; demand for electricity $C_{\mathrm{EL}}^{t}$, heat $C_{\mathrm{HE}}^{t}$ and cooling energy $C_{\mathrm{CO}}^{t}$ at time $t$; distance to the source of electricity $l_{i}^{\mathrm{EL}}, i \in I$, heat $l_{j}^{\mathrm{HE}}, j \in J$ and cooling energy $l_{d}^{\mathrm{CO}}, d \in D$. Solution to the problem should include: electricity generation $\mathbf{w}=\left(w_{1}, \ldots, w_{i}\right)^{\mathrm{T}}$; heat generation $\mathbf{h}=\left(h_{1}, \ldots\right.$, $\left.h_{j}\right)^{\mathrm{T}}$; cooling generation $\mathbf{q}=\left(q_{1}, \ldots, q_{d}\right)^{\mathrm{T}}$. It is necessary to minimize the function of total costs of the load-controlled consumer energy system that has the form:

$$
\begin{aligned}
& Z(w, h, q)=\sum_{t=1}^{p}\left\{\begin{array}{l}
\sum_{m=1}^{i} \alpha_{m}\left[Z_{t}^{\mathrm{EL}}\left(w_{m}, S_{t, m}^{\mathrm{EL}}\right)+Z^{\mathrm{S}-\mathrm{B}}\left(w_{m}\right)+Z_{t}^{\mathrm{S} \_\mathrm{E}}\left(w_{m}\right)+\right. \\
\left.+Z^{\mathrm{N} \_\mathrm{B}}\left(w_{m}, l_{m}^{\mathrm{EL}}\right)+Z_{t}^{\mathrm{N} \_\mathrm{E}}\left(w_{m}, l_{m}^{\mathrm{EL}}\right)\right]+\sum_{n=1}^{j} \beta_{n}\left[Z_{t}^{\mathrm{HE}}\left(h_{n}, S_{t, n}^{\mathrm{HE}}\right)+\right. \\
\left.+Z_{-}^{\mathrm{S} \_\mathrm{B}}\left(h_{n}\right)+Z_{t}^{\mathrm{S}-\mathrm{E}}\left(h_{n}\right)+Z^{\mathrm{N} \_\mathrm{B}}\left(h_{n}, l_{n}^{\mathrm{HE}}\right)+Z_{t}^{\mathrm{N} \_\mathrm{E}}\left(h_{n}, l_{n}^{\mathrm{HE}}\right)\right]+ \\
+\sum_{r=1}^{d} \gamma_{r}\left[Z_{t}^{\mathrm{CO}}\left(q_{r}, S_{t, r}^{\mathrm{CO}}\right)+Z^{\mathrm{S} \_\mathrm{B}}\left(q_{r}\right)+Z_{t}^{\mathrm{S} \_\mathrm{E}}\left(q_{r}\right)+\right. \\
\left.+Z^{\mathrm{N} \_\mathrm{B}}\left(q_{r}, l_{r}^{\mathrm{CO}}\right)+Z_{t}^{\mathrm{N} \_\mathrm{E}}\left(q_{r}, l_{r}^{\mathrm{CO}}\right)\right]
\end{array}\right\} \rightarrow \min \quad(1) \\
& \boldsymbol{\alpha}=\left(\alpha_{1}, \ldots, \alpha_{i}\right)^{\mathrm{T}}, \alpha_{m} \in\{0,1\}, \boldsymbol{\beta}=\left(\beta_{1}, \ldots, \beta_{j}\right)^{\mathrm{T}}, \beta_{n} \in\{0,1\}, \gamma=\left(\gamma_{1}, \ldots, \gamma_{l}\right)^{\mathrm{T}}, \gamma_{r} \in\{0,1\}, \\
& \mathbf{w}=\left(w_{1}, \ldots, w_{i}\right)^{\mathrm{T}}, w \in \mathbb{R}^{i}, \mathbf{h}=\left(h_{1}, \ldots, h_{j}\right)^{\mathrm{T}}, h \in \mathbb{R}^{j}, \mathbf{q}=\left(q_{1}, \ldots, q_{d}\right)^{\mathrm{T}}, q \in \mathbb{R}^{d}, S_{t, m}^{\mathrm{EL}} \in \mathbb{R}^{m \times p}, \\
& S_{t, n}^{\mathrm{HE}} \in \mathbb{R}^{n \times p}, S_{t, r}^{\mathrm{CO}} \in \mathbb{R}^{r \times p}, l_{m}^{\mathrm{EL}} \in \mathbb{R}^{i}, l_{n}^{\mathrm{HE}} \in \mathbb{R}^{j}, l_{r}^{\mathrm{CO}} \in \mathbb{R}^{d}, t=\overline{1, p}, m=\overline{1, i}, n=\overline{1, j}, r=\overline{1, d} .
\end{aligned}
$$

Subject to:

$$
\begin{gathered}
w_{i}=w_{i 0} K_{i}^{\mathrm{TR}} K_{i}^{\mathrm{EF}} \lambda_{i}, i \in I ; h_{j}=h_{j 0} K_{j}^{\mathrm{TR}} K_{j}^{\mathrm{EF}} \lambda_{j}, j \in J ; q_{d}=q_{d 0} K_{d}^{\mathrm{TR}} K_{d}^{\mathrm{EF}} \lambda_{d}, d \in D ; \\
C_{\mathrm{EL}}^{t} \leq \sum_{m=1}^{i} w_{m}^{t} ; C_{\mathrm{HE}}^{t} \leq \sum_{n=1}^{j} h_{n}^{t} ; C_{\mathrm{CO}}^{t} \leq \sum_{r=1}^{d} q_{r}^{t} \\
w \geq 0 ; h \geq 0 ; q \geq 0 ; \\
\underline{w} \leq w_{i} \leq \bar{w}, i \in I ; \underline{h} \leq h_{j} \leq \bar{h}, j \in J ; \underline{q} \leq q_{d} \leq \bar{q}, d \in D ; \\
\underline{\eta} \leq \frac{w_{v}}{h_{v}} \leq \bar{\eta}, v \in I_{\mathrm{E}}, I_{\mathrm{E}} \subset I, v \in J_{\mathrm{E}}, J_{\mathrm{E}} \subset J
\end{gathered}
$$


where $Z_{t}^{\mathrm{EL}}\left(w_{m}, S_{t, m}^{\mathrm{EL}}\right), Z_{t}^{\mathrm{HE}}\left(h_{n}, S_{t, n}^{\mathrm{HE}}\right), . Z_{t}^{\mathrm{CO}}\left(q_{r}, S_{t, r}^{\mathrm{CO}}\right) .-$ calculated costs of electricity, heat and cooling, respectively; $Z^{\mathrm{S} \_\mathrm{B}}\left(w_{m}\right), Z^{\mathrm{S} \_\mathrm{B}}\left(h_{n}\right), Z^{\mathrm{S} \_\mathrm{B}}\left(q_{r}\right)$ - calculated construction costs of the source of electricity, heat and cooling, respectively; $Z_{t}^{\mathrm{S} \_\mathrm{E}}\left(w_{m}\right), Z_{t}^{\mathrm{S}-\mathrm{E}}\left(h_{n}\right), Z_{t}^{\mathrm{S}-\mathrm{E}}\left(q_{r}\right)$ - calculated operational costs of the source of electricity, heat and cooling, respectively; $Z^{\mathrm{N} \_\mathrm{B}}\left(w_{m}, d_{m}^{\mathrm{EL}}\right), \quad Z^{\mathrm{N} \_\mathrm{B}}\left(h_{n}, d_{n}^{\mathrm{HE}}\right), \quad Z^{\mathrm{N} \_\mathrm{B}}\left(q_{r}, d_{r}^{\mathrm{CO}}\right)-$ calculated construction costs of a network from the source of electricity, heat and cooling, respectively, to the consumer; $Z_{t}^{\mathrm{N}-\mathrm{E}}\left(w_{m}, d_{m}^{\mathrm{EL}}\right), Z_{t}^{\mathrm{N}-\mathrm{E}}\left(h_{n}, d_{n}^{\mathrm{HE}}\right), Z_{t}^{\mathrm{N}-\mathrm{E}}\left(q_{r}, d_{r}^{\mathrm{CO}}\right)-$ calculated operational costs of the network from the source of electricity, heat and cooling, respectively, to the consumer; $p-$ period of time; $\alpha_{m}$ - electricity source state $\left(0-\right.$ off, $1-$ on); $\beta_{n}$ - heat source state $(0-$ off, $1-$ on $) ; \gamma_{r}-$ cooling source state $(0-$ off, $1-$ on $) ; K^{\mathrm{TR}}-$ the conversion factor of the primary energy resource to the required energy type; $K^{\mathrm{EF}}$ - source efficiency; $\lambda$ - energy transmission losses in the energy system components; $w_{i 0}$ - primary energy resources; $\eta-$ generated electricity to heat ratio at CHPP.

The above generalized statement was reduced to solving the problem of mixed integer linear programming [17-18].

\section{Testing on a test energy scheme}

A redundant energy supply scheme for the prosumer is built to substantiate the choice of energy sources of the prosumer to cover its own load with minimal costs for generation of electricity, heat and cooling. The redundant scheme consists of a coal-fired mini-CHPP (CCHPP), a gas-fired mini-CHP (GCHPP), an electric boiler, a heat storage, and an absorption refrigeration unit. Generating capacities include an Ingersoll Rand microturbine, an absorption refrigeration unit (ARU), a Neuron-500 container power plant unit, and an electric boiler. The generation structure of the active consumer is shown in Figure 1.

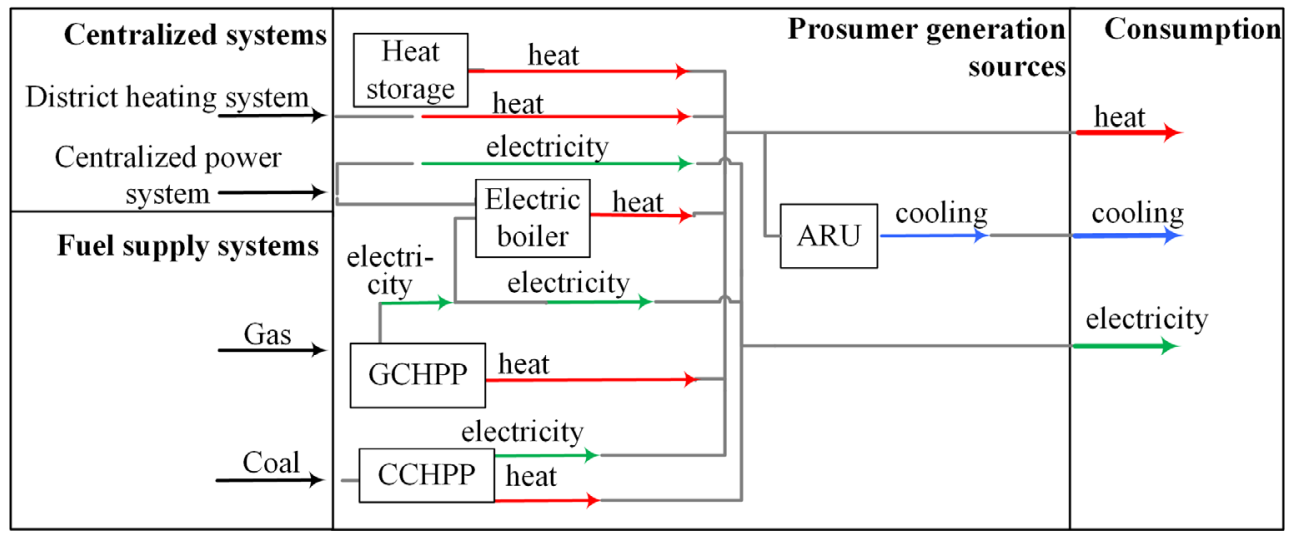

Fig. 1. A structure of controlled load consumer generation.

According to the above scheme, the sources of energy supply to the prosumer in the considered scheme are the following: the electricity sources are: centralized power system (CPS), CCHPP, GCHPP; heat sources are: district heating system (DHS), electric boiler, CCHPP, heat storage (HS), GCHPP; cooling sources are: ARU that receives heat from heat sources. 
The constructed daily electricity, heat and cooling load curves of the prosumer are presented in Figure 2.

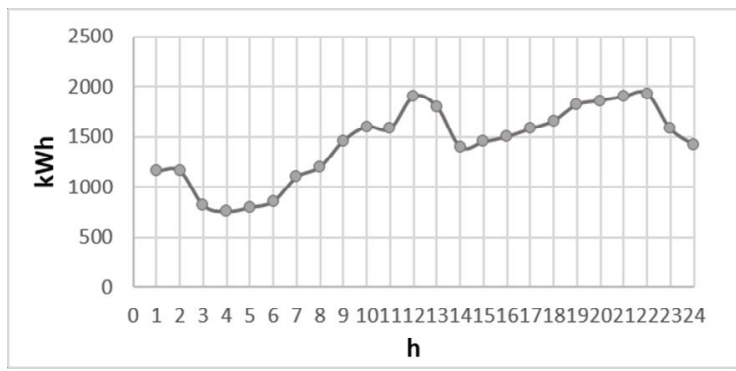

a)

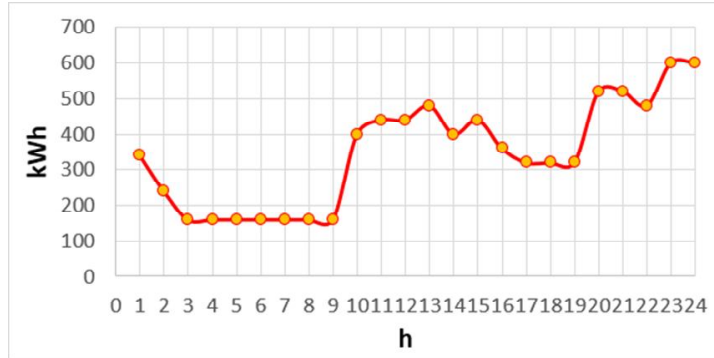

b)

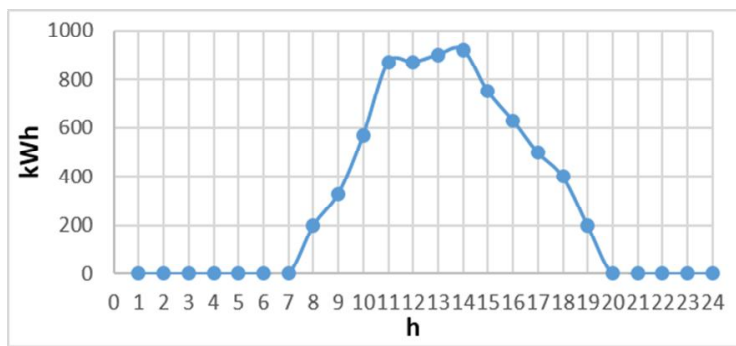

c)

Fig. 2. Daily load curve: a) electricity, b) heat and c) cooling.

The costs of various resources in the considered prosumer scheme are the following: CPS - 0.92 rub./ kWh, DHS - 0.89 rub./ kWh, gas $-8.49 \mathrm{rub} . / \mathrm{m}^{3}$, coal $-0.11 \mathrm{rub} . / \mathrm{kg}$, storage in HS $-0.01 \mathrm{rub} . \mathrm{m}^{3}$. The model takes into account the following energy transmission and storage losses in the energy system: 5\% when stored in HS, 7\% when transmitted to DHS, 7\% when transmitted to CPS. The assumed constraints include the constraints on electric boiler capacity: $h \leq 1500 \mathrm{~kW}$; on the GCHPP capacity: $12.5 \mathrm{~kW} \leq w$ $\leq 2000 \mathrm{~kW}, 18 \mathrm{~kW} \leq h \leq 4000 \mathrm{~kW}, 1.44 \leq w / h \leq 2$; on the CCHPP capacity: $100 \mathrm{~kW} \leq w$ $\leq 1500 \mathrm{~kW}, 192 \mathrm{~kW} \leq h \leq 2900 \mathrm{~kW}, 1.92 \leq w / h \leq 1.93$; on HS capacity: $30 \mathrm{~kW} \leq h \leq 583$ $\mathrm{kW}$.

We have developed the software to model the prosumer. The software is implemented in Java [19]. A set of tools implemented as a free lp_solve library for Java [20] is employed as a solver of linear programming problems.

The results of calculation for the selection of the prosumer generation sources in an intelligent electricity, heat/cooling system are presented in Figure 3. The following 
technologies were selected from the competing ones: CPS, GCHPP, CCHPP - for electricity generation; an electric boiler, GCHPP, CCHPP - for heat generation; and the use of heat from GCHPP and CCHPP - for cooling generation. Two sources are selected for cooling generation. They supply heat to ARM. The CCHPP is the most cost-effective source, but due to the limitations on the minimum possible heat supply at some hours of the day (8-00 and 19-00, see Figure 3), this source cannot be used. In this case, the GCHPP is used to cover the cooling load. The total costs of electricity, heat and cooling generation were 114864.15 rubles.

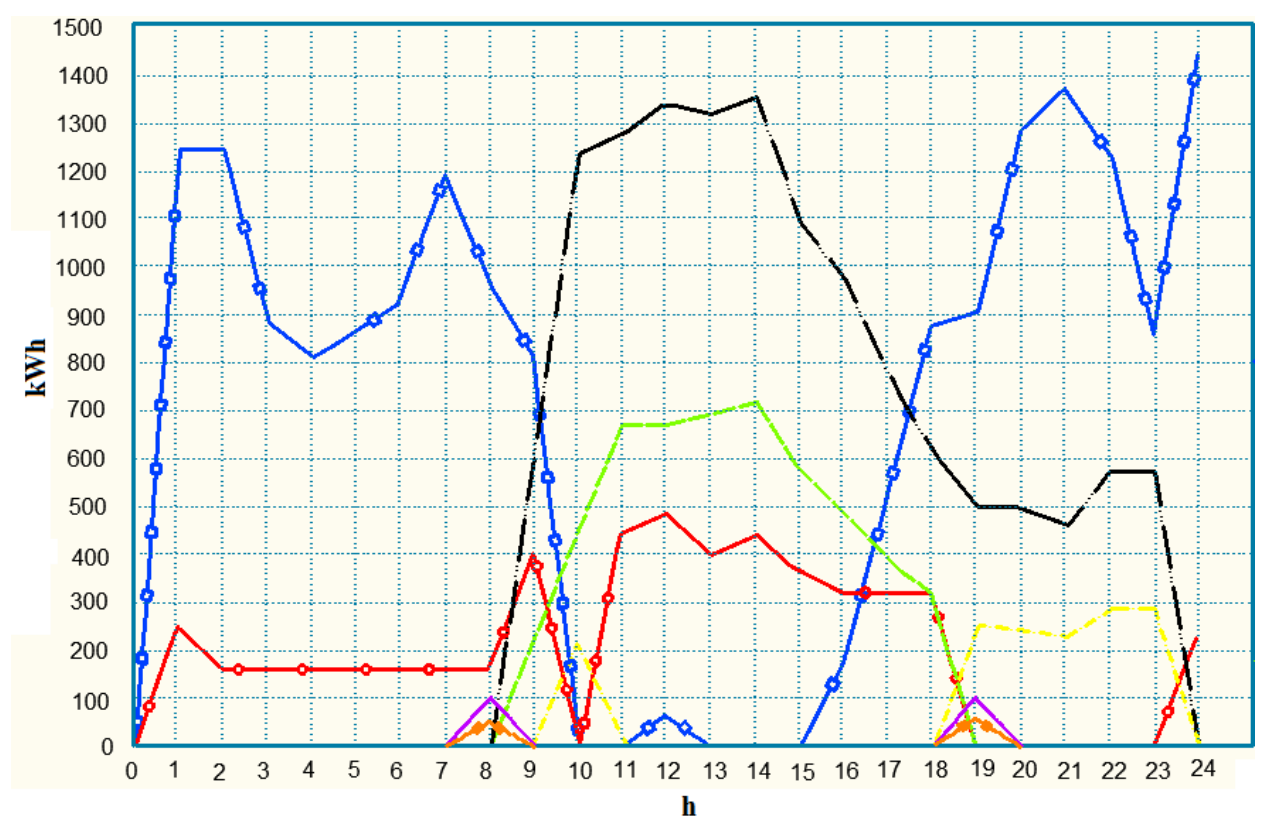

Fig. 3. The result for the determination of the rational loading of the prosumer generation sources (electric boiler - - -, GCHPP (heat) - , CCHPP (heat) --, DHS - , CPS -o-, GCHPP (electricity) -, CCHPP (electricity) - , GCHPP (cooling) $\cdots$, CCHPP (cooling) --).

\section{Conclusion}

In this research, we developed a methodology for modeling the prosumer in intelligent electricity and heat supply systems.

The most important results of the work are: a mathematical model of the prosumer in the intelligent electricity, heat and cooling systems; a method for rational management of electricity, heat and cooling generation of the prosumer in the intelligent systems to cover the load with minimal costs; a method of choosing the energy sources to cover the load with minimal costs for electricity, heat and cooling generation; software implementation of the developed methodology for the modeling of the prosumer in intelligent electric, heat/cooling systems.

The further development and extension of the started research will focus on: consideration of the wear and tear of the generating equipment during its startup/shutdown; consideration of nonlinear characteristics of equipment; consideration of the inertia nature of the processes that occur in the heat and cooling systems.

The work was carried out within framework of scientific projects III.17.4.1 of the fundamental research program of the SB RAS AAAA-A17-117030310432-9. 


\section{References}

1. N. I. Voropai and V. A. Stennikov, Izvestiya Rossiiskoi akademii nauk. Energetika, 1 (2014)

2. N. Voropai, V. Stennikov, S. Senderov, E. Barakhtenko, O. Voitov, A. Ustinov, Journal of Energy Engineering, 143 (2017)

3. N. I. Voropai, V. A. Stennikov, S. M. Senderov, E. A. Barakhtenko, L. I. Kovernikova, O. N. Voitov, T. B. Oshchepkova, L. V. Semenova, Energeticheskaya Politika, 3 (2015)

4. N. Voropai, V. Stennikov, S. Senderov, E. Barakhtenko, O. Voitov, L. Kovernikova, T. Oshchepkova, L. Semenova, Proc. of the International Conference on Problems of Critical Infrastructures, 115-121 (2015)

5. N. I. Voropai, V. A. Stennikov, E. A. Barakhtenko, Studies on Russian Economic Development, 28, 492-499 (2017)

6. H. Yang, T. Xiong, J. Qiu, D. Qiu, Z. Y. Dong, Applied Energy, 167, 353-365 (2016)

7. R. Zafara, A. Mahmoodb, S. Razzaqc, W. Alia, U. Naeema, Renewable and Sustainable Energy Reviews, 82, 1675-1684 (2018)

8. D. Patteeuw, K. Bruninx, A. Arteconi, E. Delarue, W. D’haeseleer, L. Helsen. Applied Energy, 151, 306-319 (2015)

9. N. Neyestani, M. Yazdani-Damavandi, M. Shafie-khah, G. Chicco, J. P. S. Catalão, IEEE Transactions on Smart Grid, 6, 1748-1762 (2015)

10. S. van der Stelt, T. AlSkaif, W. van Sark, Applied Energy, 209, 266-276 (2018)

11. E. Barbour, M. C. González, Applied Energy, 215, 356-370 (2018)

12. S. Samsatli, N. J. Samsatli, Applied Energy, 220, 893-920 (2018)

13. M. La Scala, A. Vaccaro, A. F. Zobaa. Applied Thermal Engineering 71, 658-666 (2014)

14. R. Rezaeipour, A. Zahedi, Solar Energy, 157, 227-235 (2017)

15. F. Samira, M. Pierre, B. Gwenaelle, M. Francois, Energy, 45, 12-22 (2012)

16. J. Aghaei, Mohammad-Iman Alizadeh. Energy, 55, 1044-1054 (2013)

17. M. J. Todd, Mathematical Programming, 91, 417-436 (2002)

18. G. B. Dantzig, M. N. Thapa, Linear Programming 2: Theory and Extensions (2003)

19. J. Gosling, B. Joy, G. Steele, G. Bracha, A. Buckley, The Java Language Specification (2014)

20. lp_solve reference guide. URL: http://lpsolve.sourceforge.net/5.5/ 